\title{
Quantitative Analysis on the Correlation between Risks: Empirical Evidence from Banks in United Kingdom
}

\author{
Sheila Nu Nu Htay, Syed Ahmed Salman 2 \\ 1Assistant Lecturer and PhD. Programme coordinator Institute of Islamic Banking and Finance, International \\ Islamic University Malaysia. \\ 2PhD. Candidate at IIUM Institute of Islamic Banking and Finance, Malaysia
}

\begin{abstract}
Financial institutions or banks are faced with several types of risks that are uniquely related to the nature of the industry. Therefore it is a must for banks to have risk mitigation methods in order to maintain its competitiveness and sustainability. For the purpose of this paper, four unique risks related to the banking industry will be discussed, as well as to provide empirical study on the relationship between these risks. These risks are liquidity risk, operational risk, credit risk and market risk. The focus of this study is on ten listed banks in United Kingdom with complete secondary data from the year 2002 to 2011. Liquidity risk is measured by the ratio of total loans to total deposits, operational risk is calculated based on two ratios, i.e. the ratio of operating expenses to total assets and the ratio of non-performing loans to total loans. Credit risk is based on the probability of default based on Altman's z score equation and market risk is calculated based on the standard deviation of quarterly stock returns. The findings show the evidence that there is a relationship between tested risk and it is expected that the findings will be the interest of the bankers to see which risk is the source of other risks.
\end{abstract}

Key words: Operational risk, liquidity risk, credit risk, market risk and UK

\section{Introduction}

Financial institutions like many other profit oriented organisationshave the ultimate objective of maximising shareholders wealth. Shareholders wealth, according to Benton, James, Donald (2005) can be measured by the market value of stocks and dividends paid. However, due to the nature of financial institutions as financial intermediaries, they are usually faced with several unique risks of the banking industry. Some of these unique risks are credit risk, interest rate risk, liquidity risk, market risk, operational risk, capital risk and fraud risk

Therefore, financial institutions accept these risks in order to gain profit. Risk management of these institutions are basically to maintain the balance between risk and return with shareholder's wealth maximisation in mind. The basic theory of financial management is that, if the risks are high then the required rate of return should be higher in order to gain profitability. There are unique risks related to the banking industry. However, for our purpose of study only four risks will be discussed. These risks are liquidity risk, operational risk, credit risk and market risk. This paper focuses on the risks faced by the banks in United Kingdom (UK) because it is one of the leading countries which have stable banking system.

Prior researchers have highlighted the important role of risks in banks. However, to researchers' knowledge, no research has focused on examining the correlation among four risks. Therefore, the objective of this paper is to show the correlation among the liquidity risk, operational risk, credit risk and market risk in UK banks.

This paper is discussed in five sections. The second section provides the overview of the UK economy. The third section elaborates the definitions of liquidity risk, operational risk, credit risk and market risk. The third section explains the research methodology. The fourth section describes the findings of this research and the last section concludes.

\section{I.II. OVERVIEW OF ECONOMY: UNITED KINGDOM}

\begin{tabular}{|c|c|c|c|c|c|c|c|c|c|c|}
\hline Year & 2002 & 2003 & 2004 & 2005 & 2006 & 2007 & 2008 & 2009 & 2010 & 2011 \\
\hline $\begin{array}{c}\text { GDP } \\
\text { (US\$ in billions) }\end{array}$ & 1,612 & 1,860 & 2,201 & 2,281 & 2,445 & 2,813 & 2,636 & 2,171 & 2,252 & 2,432 \\
\hline
\end{tabular}

(Source: The World Bank accessible at data.worldbank.org/).

The above table shows the GDP of United Kingdom from the year 2002 until 2011 denominated by US dollars in billions The economy of United Kingdom has long been one of the strongest in the world and it is placed seventh in the ranking of world nominal GDP. 
However, in the second quarter of year 2008, United Kingdom is faced with recession where the last recession was in 1991. This recession affects the GDP of United Kingdom for one and a half year where it ends in fourth quarter of year 2009. And it can be seen from the table above that the GDP in the year 2008 dropped from US\$2.636 trillion to US\$2.171 trillion in the year 2009 which is a drop of $17.64 \%$. According to Tang (2008), this drop is mainly caused by financial market turmoil and increase in commodity prices which strains the economic performance of the country.

Slowly the economy is increasing and it is trying to come up to its original standings as stated in the table for the year 2010 and 2011. It is because the United Kingdom implemented several policies that were suggested by the International Monetary Fund where they provide more liquidity, financial sector rules are reformed and macroeconomic policies are loosen to ease the economy.

\section{Definitions Of Liquidity Risk, Operational Risk, Credit Risk And Market Risk}

This section explains the definitions of liquidity risk, operational risk, credit risk and market risk. Liquidity risk is defined as the inability of the bank to quickly convert their assets into cash when needed. Liquidity in the banking industry is extremely crucial because depositors did not simply deposit their money for a long period of time. Banks being a financial intermediary will provide financing to individuals or organizations in need of financial support by utilising these deposits. The reason banks are instructed by the central banks, country-wise to utilise only a certain percentage of deposits to service the financing needs is to ensure that the money are available to depositors when they want to take them out (ECB, 2009; Bonfim\& Kim, 2012).

Operational risk refers to the inefficiency and ineffectiveness of banks' operations which includes management information system and human resources. Any problems with the information system or the infrastructure itself will be considered as a major loss to the bank. Human resources are also a factor in contributing to operational risk because any frauds, corruptions and embezzlements may cause a huge loss to the bank. Therefore, it is important for banks to monitor their personnel very closely so that this risk will not arise (Doerig, 2003; Geiger, n.d.; BCBS, 2011).

Credit risk usually refers to the defaults in either financing services or investments. In most of the cases, it happens due to defaults by their customers in paying the instalments. These defaults may be intentional or unintentional. When it is intentional, it is because the customers basically have no discipline in paying back their financing. However, this issue may be settled in court where the customers are instructed to either pay back the amount due or their assets will be liquidated and they will be declared bankrupt. It is the unintentional ones that need to be monitored (Varotto, 2011; BNM, 2011; Vodová, n.d.).

Market risk is a systematic risk arises when there is a change in the market prices of investment portfolio assets of the bank. It can have an effect on the profitability of the bank where their investments would either yield a lower return or incur loss. As discussed before, wealth maximisation of shareholders is the main objective of the banks and thus, any reduce in profit or incur of loss would consequently reduce the wealth of the shareholders. Banks should be careful in choosing the assets for investment and to fully diversify it to ensure that the portfolio can provide the maximum profit to increase the shareholder's wealth. (RBAB,1996; Trence, n.d.).

This section is mainly focused on the relationship between the four selected risks based on the existing literature which highlights a relationship between these risks. According to Gregoriou (2009), a study has been done to examine the reaction of stock returns to operational risk. The result shows that any operational risk events that occur will have a negative impact on the stock returns. This means that with the materialisation of operational risk, the value of stocks which represents one of the shareholder's wealth will decrease. Since the standard deviation of stock returns are used as our proxy for market risk, we may generalise that an increase in operational risk will have a positive impact on market risk. Logically, any undesired events that had materialised which affect the bank's performance will also affect the stock returns.

According toImbierowicz and Rauch (2012), the relationship between liquidity risk and credit risk exists by highlighting the theoretical aspect and they find that there is no reliable relationship can be derived. It means that liquidity risk has no impact whatsoever on credit risk and vice versa.

The relationship between operational risk and credit risk, although not available in existing literatures can be derived. Operational risk is something that arises from factors inside the banks while credit risk arises from the inability of customers to pay back their financing. Although the operational risk is internal risk and credit risk is something external, the least efficient banks might not monitor the payments of customers and thus, it can be expected that there is a positive relationship between two risks.

Similarly, the relationship between operational and liquidity risk is also not available in existing literature. Operational risk arises from failures of internal processes while liquidity risk arises from the inability to convert assets into cash. The management of the bank must ensure that each asset that they invested must be liquid in order to meet short term obligations. Therefore, if there is an increase in liquidity risk, we can say that 
the management fails on asset investment decision which results to an increase in operational risk. The same scenario can be used if investments in assets are highly liquid; this means that the management has made a correct decision. From this point of view, we can conclude that operational risk has a positive relationship with liquidity risk.

\section{Research Methodology}

This paper focuses on ten public listed banks in UK from 2002 to 2011. Financial Services Authority (FSA) is an independent non-government agency however were given statutory powers by the Financial Services and Markets Act 2000 which sole purpose is to regulate the financial services industry in the United Kingdom. There are numerous banks that were listed by the FSA based on several subdivisions. From the current list of banks (as of November 2012), the list is accessible at the FSA website.

This study uses correlation to see the four risk faced by the banks. The representation of these variables will be explained below:

1. Liquidity risk is calculated based on the ratio of total loans to total deposits represented by LR.

2. Operational risk is calculated based on two ratios. The first one is the ratio of operating expenses to total assets represented by OR1, another is the ratio of non-performing loans to total loans represented by OR2.

3. Credit risk is based on the probability of default based on Altman's z score equation and represented as CR.

4. Market risk is calculated based on the standard deviation of quarterly stock returns and represented by MR.

\section{Findings On Correlation Among The Risks}

The correlation is done on the 10 banks mentioned earlier with data from the year 2002 until 2011 and the results will be discussed separately according to each bank. The purpose is to see whether there are any significant relationships between credit risk, liquidity risk, operational risk and stock returns. It is to be noted however that the discussion of correlation resultsare only based on the sign, whether positive or positive only and the values are deemed to be insignificant.

Bank A

\begin{tabular}{|l|l|l|l|l|l|}
\hline & LR & OR1 & OR2 & CR & MR \\
\hline LR - Pearson Correlation & 1 & -0.322 & 0.590 & -0.414 & 0.434 \\
\hline OR1 - Pearson Correlation & -0.322 & 1 & -0.430 & -0.053 & 0.108 \\
\hline OR2 - Pearson Correlation & 0.590 & -0.430 & 1 & 0.095 & 0.679 \\
\hline CR - Pearson Correlation & -0.414 & -0.053 & 0.095 & 1 & 0.141 \\
\hline MR - Pearson Correlation & 0.434 & 0.108 & 0.679 & 0.141 & 1 \\
\hline
\end{tabular}

The correlation between liquidity risk and operational risk (OR1) shows an inverse relationship by the value of 0.322. It means that for every unit increase of liquidity risk, the value of operational risk will decrease. However, another correlation between liquidity and the second operational risk (OR2) shows the result of 0.590. The relationship is now positive where an increase in a unit of liquidity risk would result to an increase of operational risk.

The correlation between liquidity risk and credit risk shows a negative relationship where the value of the coefficient is -0.414 . From this relationship it can be said that an increase in liquidity risk will reduce credit risk.

The correlation between operational risk (OR1) and its counterpart (OR2) surprisingly shows the result of 0.430 , which means that for this bank; an increase in one measure of operational risk does not really increase the operational risk of the other measure. In fact an increase in OR1 decreases the value of OR2.

The correlation between the operational risk (OR1) and credit risk shows a negative relationship with the coefficient value of -0.053 . However, when the second measure of operational risk (OR2) is correlated with credit risk, it shows that an increasing relationship with the coefficient value of 0.095 . This shows that an increase of operational risk may either decrease of increase the credit risk.

The correlation between every individual risk (liquidity risk, operating risk and credit risk) and market risk shows a positive relationship with each coefficient shown in the table above. This means that market risk will increase when there is an increase of every other risk. 
Quantitative Analysis on the Correlation between Risks: Empirical Evidence from Banks in United

Bank B

\begin{tabular}{|l|l|l|l|l|l|}
\hline & LR & OR1 & OR2 & CR & MR \\
\hline LR - Pearson Correlation & 1 & -0.420 & 0.481 & -0.013 & 0.584 \\
\hline OR1 - Pearson Correlation & -0.420 & 1 & -0.607 & -0.307 & -0.328 \\
\hline OR2 - Pearson Correlation & 0.481 & -0.607 & 1 & 0.583 & 0.124 \\
\hline CR - Pearson Correlation & -0.013 & -0.307 & 0.583 & 1 & -0.267 \\
\hline MR - Pearson Correlation & 0.584 & -0.328 & 0.124 & -0.267 & 1 \\
\hline
\end{tabular}

The correlation between liquidity risk and operational risk (OR1) has an inverse relationship. It is because the value of the coefficient is -0.420 , which means that for every increase of liquidity risk, the operational risk will decrease. However, the relationship differs when it comes to the second measure of operational risk (OR2) because it has a positive relationship. It is because the coefficient value is 0.481 which tells that the value of operational risk will increase if there is any increase in liquidity risk.

The correlation between liquidity risk and credit risk also shows an inverse relationship, where an increase in liquidity risk will increase credit risk evident from the coefficient value of -0.013 . With market risk on the other hand, the correlation shows positive relationship where an increase of liquidity risk will increase market risk based on the evidence that the value of the coefficient is 0.584 .

Interestingly, the correlation between operational risk (OR1) and all other separate risks shows an inverse relationship by the negative value of the coefficient. This means that an increase in OR1 may result to a decrease of other risks.

The correlation between operational risk (OR2) and credit as well as market risk shows a positive relationship where the coefficient value is both positive. This implies that an increase in OR2 may result to an increase of credit and market risk.

Meanwhile, the correlation between credit risk and market risk results in an inverse relationship where an increase in credit risk may decrease the market risk. It is evident based on the coefficient value of -0.267 .

Bank C

\begin{tabular}{|l|l|l|l|l|l|}
\hline & LR & OR1 & OR2 & CR & MR \\
\hline LR - Pearson Correlation & 1 & -0.391 & 0.525 & -0.021 & 0.339 \\
\hline OR1 - Pearson Correlation & -0.391 & 1 & -0.734 & -0.824 & 0.020 \\
\hline OR2 - Pearson Correlation & 0.525 & -0.734 & 1 & 0.710 & 0.040 \\
\hline CR - Pearson Correlation & -0.021 & -0.824 & 0.710 & 1 & -0.294 \\
\hline MR - Pearson Correlation & 0.339 & 0.020 & 0.040 & -0.294 & 1 \\
\hline
\end{tabular}

Correlation between liquidity risk and operation risk (OR1) and credit risk shows an inverse relationship where an increase of liquidity may result to a decrease of operational and credit risk. This is evident from the coefficient value of -0.391 and -0.021 respectively.

The correlation between operational risks (OR1) also has an inverse relationship with other risks except market risk. For every increase in operational risk (OR1), there may be a decrease in the liquidity risk, operational risk of different measure (OR2) and credit risk. While its increase will also increase the market risk evident from the positive coefficient value. As mentioned, OR2 and OR1 have an inverse relationship. However, correlation between OR2 and other risks have a positive relationship represented by the positive value in the coefficient. Therefore, an increase in OR2 may increase other risks as well, but not OR1.

The coefficient value of -0.294 shows an inverse relationship between credit risk and market risk where an increase in credit risk may reduce market risk. It is represented by the negative value in the table.

$\underline{\text { Bank D }}$

\begin{tabular}{|l|l|l|l|l|l|}
\hline & LR & OR1 & OR2 & CR & MR \\
\hline LR - Pearson Correlation & 1 & 0.704 & 0.742 & -0.564 & 0.213 \\
\hline OR1 - Pearson Correlation & 0.704 & 1 & 0.824 & -0.589 & 0.408 \\
\hline OR2 - Pearson Correlation & 0.742 & 0.824 & 1 & -0.790 & 0.037 \\
\hline CR - Pearson Correlation & -0.564 & -0.589 & -0.790 & 1 & 0.184 \\
\hline MR - Pearson Correlation & 0.213 & 0.408 & 0.037 & 0.184 & 1 \\
\hline
\end{tabular}


Correlation result of liquidity risk and other risks shows positive relationship except for credit risk. Positive relationship is evident based on the positive value of the coefficient and vice versa. This implies that a change in liquidity risk may impact operational and market risk positively. However, its change will affect credit risk as shown in the table.

The same thing goes with operational risk (OR1 and OR2) where its correlation has a positive impact on other risks but not credit risk. This implies that an increase in operational risk may increase other risks, but it will reduce credit risk.

The correlation result shows a positive relationship between market risk and other risks. It is denoted by the positive value of coefficient as stated in the table.

$\underline{\text { Bank E }}$

\begin{tabular}{|l|l|l|l|l|l|}
\hline & LR & OR1 & OR2 & CR & MR \\
\hline LR - Pearson Correlation & 1 & 0.703 & -0.786 & -0.189 & -0.203 \\
\hline OR1 - Pearson Correlation & 0.703 & 1 & -0.934 & -0.269 & -0.072 \\
\hline OR2 - Pearson Correlation & -0.786 & -0.934 & 1 & 0.159 & 0.124 \\
\hline CR - Pearson Correlation & -0.189 & -0.269 & 0.159 & 1 & -0.231 \\
\hline MR - Pearson Correlation & -0.203 & -0.072 & 0.124 & -0.231 & 1 \\
\hline
\end{tabular}

The correlation between liquidity risk and other risks shows that there is a positive impact on OR1, but negative impact on the others. It is evident from the positive and negative value of the coefficient stated in the table above. An increase in liquidity risk may not only increase OR1, but it may also decrease other risks.

The relationship between OR1 also has a negative impact on other risks except for liquidity risk as mentioned above. An increase in OR1 may decrease the value of OR2, credit risk and market risk.

As mentioned above, OR2 has an inverse relationship with liquidity risk and OR1. However, it has positive relationship with credit and market risk with positive coefficient value. Which means, an increase of OR2 may also increase credit and market risk.

The coefficient value of -0.231 shows an inverse relationship between credit risk and market risk as evident from its negative sign. It can be said that an increase in credit risk may decrease the value of market risk.

$\underline{\text { Bank F }}$

\begin{tabular}{|l|l|l|l|l|l|}
\hline & LR & OR1 & OR2 & CR & MR \\
\hline LR - Pearson Correlation & 1 & 0.726 & 0.020 & -0.934 & 0.561 \\
\hline OR1 - Pearson Correlation & 0.726 & 1 & 0.495 & -0.767 & 0.185 \\
\hline OR2 - Pearson Correlation & 0.020 & 0.495 & 1 & -0.195 & -0.037 \\
\hline CR - Pearson Correlation & -0.934 & -0.767 & -0.195 & 1 & -0.546 \\
\hline MR - Pearson Correlation & 0.561 & 0.185 & -0.037 & -0.546 & 1 \\
\hline
\end{tabular}

The correlation of liquidity risk and other risks are positively related except credit risk. It is evident by the positive value of the coefficient. It shows that an increase in liquidity may increase operational risk and market risk but it will decrease credit risk.

The same goes with operational risk (OR1) where every other risk is positively related except credit risk. An increase in OR1 may increase operational risk and market risk but it will decrease credit risk. It is evident from the sign of the coefficient value where a positive value represents positive relationship and negative value represents inverse relationship between the variables. The correlation result or OR2 with other risks are also the same with the result of OR1. However, its correlation with market risk is also negatively related with credit risk.

The correlation between credit risk and other risks are inversely related where the coefficient value is negative. Therefore, it can be said that every credit risk increase for this particular bank will decrease every other risks under discussion.

Finally, the correlation between credit risk and market risk are inversely related that every increased credit risk may decrease market risk. The negative relationship is evident from the coefficient value of -0.546 . 
Quantitative Analysis on the Correlation between Risks: Empirical Evidence from Banks in United

$\underline{\text { Bank G }}$

\begin{tabular}{|l|l|l|l|l|l|}
\hline & LR & OR1 & OR2 & CR & MR \\
\hline LR - Pearson Correlation & 1 & 0.571 & -0.375 & -0.566 & 0.003 \\
\hline OR1 - Pearson Correlation & 0.571 & 1 & -0.624 & -0.831 & -0.159 \\
\hline OR2 - Pearson Correlation & -0.375 & -0.624 & 1 & 0.877 & 0.280 \\
\hline CR - Pearson Correlation & -0.566 & -0.831 & 0.877 & 1 & 0.327 \\
\hline MR - Pearson Correlation & 0.003 & -0.159 & 0.280 & 0.327 & 1 \\
\hline
\end{tabular}

The correlation between liquidity risk and operational risk (OR1) and market risk shows a positive relationship with coefficient values of 0.571 and 0.003 respectively. This means that for every increase in liquidity risk, OR1 and market risk may also increase. The opposite goes to the correlation of liquidity risk with another measure of operational risk (OR2) and credit risk where the result shows inverse relationship with coefficient values of -0.375 and -0.566 respectively. It implies that any increase in liquidity risk may decrease OR 2 and credit risk.

The correlation between OR1 and other risks are inversely related except for liquidity risk as discussed above. It is evident from the negative values of correlation coefficient as stated in the table above. It implies that any increase in OR1 may decrease OR2, credit risk and market risk but it may perhaps decrease liquidity risk.

The correlation of operational risk (OR2) with liquidity and OR1 are clearly discussed above. However, its correlation with credit risk and market risk shows positive relationship. It is evident since the coefficient values are positive which are 0.877 and 0.280 . Therefore, an increase in OR2 may increase the value of credit risk and market risk.

The correlation between credit risk and market risk shows the coefficient value of 0.327 which means that it is positively related. An increase in credit risk may have an impact on market risk where the value might increase.

$\underline{\text { Bank H }}$

\begin{tabular}{|l|l|l|l|l|l|}
\hline & LR & OR1 & OR2 & CR & MR \\
\hline LR - Pearson Correlation & 1 & 0.330 & -0.619 & -0.552 & 0.626 \\
\hline OR1 - Pearson Correlation & 0.330 & 1 & 0.113 & -0.827 & 0.621 \\
\hline OR2 - Pearson Correlation & -0.619 & 0.113 & 1 & 0.195 & -0.259 \\
\hline CR - Pearson Correlation & -0.552 & -0.827 & 0.195 & 1 & -0.740 \\
\hline MR - Pearson Correlation & 0.626 & 0.621 & -0.259 & -0.740 & 1 \\
\hline
\end{tabular}

Correlation result of liquidity risk and other risks shows positive relationship except for operational risk (OR2) and credit risk. Positive relationship is evident based on the positive value of the coefficient and vice versa. This implies that a change in liquidity risk may impact OR1 and market risk positively. Simultaneously, its increase also would result to a negative impact to the OR2 and credit risk.

The correlation between OR1 and its counterpart (OR2) shows a positive relationship with the coefficient value of 0.113 . Similarly, it also has a positive relationship with market risk with the coefficient value of 0.621 . This implies that an increase in OR1 may increase its counterpart and market risk. However, OR1 after being correlated with credit risk resulted to an inverse relationship with coefficient value of -0.827 which implies that an increase in OR1 may increase the value of credit risk.

The correlation between OR2 and credit risk is positively related while correlation with market risk is negatively related. It is evident from the coefficient values of 0.195 and -0.259 respectively where an increase in OR2 might increase credit risk, but at the same time it will reduce market risk.

The correlation between credit risk and market risk shows the coefficient value of -0.740 which means that it is inversely related. An increase in credit risk may have an impact on market risk where the value might decrease.

Bank I

\begin{tabular}{|l|l|l|l|l|l|}
\hline & LR & OR1 & OR2 & CR & MR \\
\hline LR - Pearson Correlation & 1 & -0.510 & -0.294 & -0.421 & 0.836 \\
\hline OR1 - Pearson Correlation & -0.510 & 1 & -0.004 & 0.036 & -0.420 \\
\hline OR2 - Pearson Correlation & -0.294 & -0.004 & 1 & 0.174 & -0.401 \\
\hline CR - Pearson Correlation & -0.421 & 0.036 & 0.174 & 1 & -0.652 \\
\hline MR - Pearson Correlation & 0.836 & -0.420 & -0.401 & -0.652 & 1 \\
\hline
\end{tabular}


The correlation results between liquidity risk and other risks are negatively related except in the case of market risk. The negative relationship is evident based on the negative values of the coefficient values and vice versa which means that an increase in liquidity risk may decrease operational risk and credit risk but at the same time it will increase market risk.

The correlation between OR1 and OR2 as well as market risk shows a negative relationship where the coefficient values are -0.004 and -0.420 respectively. It shows that and increase in OR1 might result to the decrease of OR2 and market risk. On the other hand, an increase in OR1 may also increase credit risk since it is positively related with coefficient value of 0.036 .

As discussed above, OR2 has inverse relationships with liquidity risk and OR1. It also has an inverse relationship with market risk where the coefficient value is -0.401 which means than an increase in OR2 may decrease market risk. However, it has positive relationship with credit risk where an increase in OR2 will increase credit risk which is evident from the coefficient value of 0.174 .

Credit risk and market risk is basically inversely related since the correlation value is negative which is -0.652. It means that an increase in credit risk may cause an increase to the market risk.

$\underline{\text { Bank J }}$

\begin{tabular}{|l|l|l|l|l|l|}
\hline & LR & OR1 & OR2 & CR & MR \\
\hline LR - Pearson Correlation & 1 & -0.239 & -0.563 & 0.033 & 0.092 \\
\hline OR1 - Pearson Correlation & -0.239 & 1 & -0.494 & 0.470 & -0.572 \\
\hline OR2 - Pearson Correlation & -0.563 & -0.494 & 1 & -0.372 & 0.443 \\
\hline CR - Pearson Correlation & 0.033 & 0.470 & -0.372 & 1 & -0.358 \\
\hline MR - Pearson Correlation & 0.092 & -0.572 & 0.443 & -0.358 & 1 \\
\hline
\end{tabular}

The correlation between liquidity risk and operational risks (both OR1 and OR2) are negatively related since its coefficient values are negative which are -0.239 and -0.563 respectively. However, it has positive relationship with credit and market risk where the values are 0.033 and 0.092 . It implies that an increase in liquidity risk might decrease operational risks but at the same time it might increase credit risk and market risk.

Interestingly, the correlation between operational risks of different measures (OR1 and OR2) for this particular bank is inversely related where the coefficient value is -0.494 . It means that a value of one operational risk may decrease the value the other. In addition, OR1 also has negative relationship with market risk where the coefficient value is -0.572 which means that an increase in OR1 may decrease market risk. However, OR1 has positive impact with only one of the risks which is credit risk with coefficient value of 0.470 . it implies that an increase in OR1 may increase the credit risk.

Correlation has been done where OR2 has negative relationship with credit risk, while having positive relationship with market risk. The relationship is evident from the sign of each coefficient values which are 0.372 and 0.443 respectively. It implies that an increase in OR2 will decrease credit risk but will increase market risk.

The correlation between credit risk and market risk is also inversely related which is similar to majority of banks discussed earlier where an increase in credit risk will increase market risk. The relationship is evident from the negative sign of the coefficient value which is -0.358 .

\section{Conclusion}

In a nutshell, not every bank under study has similar risks relationship with other banks. Every banks shows different relationship between liquidity risk, operational risk, credit risk and market risk. It is probably due to the fact that different banks may have a different approach in measuring the risks. Furthermore, in mitigating the risks, different banks also may have different risk mitigation tools with different benchmarks which probably explain the differences of correlation results. Although the overall risksfor these banks are high,but the assets owned by the banks are enough to absorb the losses in case the risks materialise. From the study we also found out that there are undefined relationships between some risks where there are no existing literature. Further studies should be conducted to identify such relationships and empirically tested to strengthen such theory. 


\section{References}

[1]. Benton E. Gup, James W. Kolari, Donald R. FraserJ, Commercial banking: the management of risk (Wiley, 2005).

[2]. European Central Bank, Working Paper No. 1006: Liquidity (Risk) Concepts Definitions and Interactions. (2009).

[3]. Bonfim, Diana \& Kim Moshe, Liquidity risk in banking: is there herding? (July 2012).

[4]. Doerig, Hans-Ulrich, Operational Risks In Financial Services An Old Challenge In A New Environment

[5]. Basel Committee on Banking Supervision, Principles for the Sound Management of Operational Risk (June 2011)

[6]. Varotto, Simone, Liquidity Risk, Credit Risk, Market Risk and Bank Capital, ICMA Centre Discussion Papers in Finance DP2011-02 (January, 2011).

[7]. Bank Negara Malaysia, (2001).

[8]. Vodova, Pavla, Credit Risk as A Cause Of Banking Crises (n.d.)

[9]. Reserve Bank of Australia Bulletin, Managing Market Risk in Banks, December (1996).

[10]. Trenca, Ioan, ANALELE STIINłIFICE ALE UNIVERSITĂłII „ALEXANDRU IOAN CUZA” DIN IASI

[11]. Tomul LVI StiinŃeEconomice 2009.(n.d.).

[12]. Tang, A.A. Twin, Global Shocks Dent United Kingdom Outlook. IMF Survey Magazine: Countries \& Regions. . (2008, August 11). Retrieved on $8^{\text {th }}$ November 2012 from http://www.imf.org/external/pubs/ft/survey/so/2008/CAR081108A.htm

[13]. Gregoriou, G. N., Operational Risk toward Basel III: Best Practices and Issues in Modelling, Management and Regulation. New Jersey: John Wiley \& Sons Inc 2009).

[14]. Imbierowicz, B. \& Rauch, CThe Relationship between Liquidity Risk and Credit Risk in Banks, (2012). 